\title{
Análise multicritério na definição de vulnerabilidade ambiental
}

\author{
Análisis multicriterio en la definición de vulnerabilidad \\ ambiental
}

\section{Multicriteria analysis in environmental vulnerability definition}

\author{
Raquel Weiss \\ rweissarqui@gmail.com \\ Centro Universitário Católica de Santa Catarina, Joinville, SC \\ Luis Guilherme Aita Pippi \\ guiamy@hotmail.com \\ Universidade Federal da Santa Maria, UFSM, Santa Maria, RS
}

\begin{abstract}
Resumo: O Brasil registra milhares de incidentes anualmente, onde o Estado do Rio Grande do Sul faz parte de uma significativa parcela que sofre, principalmente, com os desastres vinculados às intensas chuvas. Assim, este artigo apresenta o diagnóstico de áreas urbanas com fragilidades ambientais quanto a desmoronamentos na cidade média de Santa Maria, na área central do Estado. Para determinar o grau de vulnerabilidade aplicou-se técnicas de sensoriamento remoto, SIG, geoprocessamento e análise de decisão multicritério. A partir de mapas de hipsometria, declividade, pedologia e uso do solo, aplicou-se a operacionalização de álgebra de mapas e processos de hierarquização analítica. Como resultado, obteve-se os níveis da fragilidade ambiental potencial (FAP) e fragilidade ambiental emergente (FAE). Concluiu-se que embora menos de $15 \%$ das áreas urbanas ou urbanizáveis estejam em áreas de risco, o perímetro urbano se encontra na maior parte em áreas de transição e medidas preventivas devem ser efetivadas para evitar um possível rompimento da estabilidade ambiental das áreas.
\end{abstract}

Palavras chaves: SIG; Geoprocessamento; Vulnerabilidade Ambiental Potencial; Vulnerabilidade Ambiental Emergente; Processo de Hierarquização Analítica.

Resumen: Brasil ha demostrado miles de incidentes cada año, en que el Estado de Rio Grande do Sul es parte de una porción significativo que sufre, principalmente, con los desastres vinculadosa las fuerteslluvias. Porlotanto, esteartículo presenta el diagnostico estudio de áreas urbanas con vulnerabilidades ambientales como deslizamientos de tierra en la ciudad mediana de Santa María, situada en la zona central del estado. Para esto se llevaron a cabo análisis mediante la aplicación de la teledetección, SIG y análisis de decisión multicriterio. Por mapas temáticos de hipsometría, pendiente, pedología y el uso de la tierra, se aplicó a la operación del álgebra de mapas y el proceso analítico jerárquico. Como resultado, se obtuvo la determinación y los niveles de fragilidad potencial (FAP) y emergente fragilidad ambiental (FAE). Se llegó a la conclusión de que, aunque menos del 15\% de las zonas urbanas o urbanizables se encuentran en zonas peligrosas, el perímetro urbano se encuentra principalmente en 
zonas de transición y deben aplicarse medidas preventivas para evitar una posible perturbación de la estabilidad Impacto ambiental de las áreas.

Palabras clave: SIG; Geoprocesamiento; Vulnerabilidad Ambiental Potencial; Vulnerabilidad Ambiental Emergente; Proceso analítico jerárquico.

\begin{abstract}
Brazil has shown thousands of incidents every year, which the State of Rio Grande do Sul is part of a significant portion that suffers mainly, from disasters related to heavy rainfalls. Thus, this paper presents a diagnostic of the urban area's vulnerability as regards as landslides in the medium city of Santa Maria, located in the central area of the State. To determine the degree of vulnerability it was applied remote sensing, GIS, geoprocessing, and multicriteria decision analysis. By means of thematic maps of hypsometry, slope, pedology, and soil use, it was applied to the algebra operation of maps and analytic hierarchy process. As a result, it was obtained the levels of potential environmental fragility (FAP) and emerging environmental fragility (FAE). It was concluded that although less than $15 \%$ of urban or no urbanisable areas are in hazardous areas, the urban perimeter is mostly in transitional areas and preventive measures should be implemented to avoid possible disruption of stability.

Keywords: GIS; Geoprocessing; Potential Environmental Vulnerability; Emerging Environmental Vulnerability; Analytical Hierarchy Process.
\end{abstract}

\title{
INTRODUÇÃO
}

Caracterizados pelos movimentos de massa de rochas, detritos e terra encosta abaixo, decorrentes das tensões de cisalhamento de materiais, os deslizamentos estão entre os principais fenômenos naturais responsáveis por significativos danos dos recursos naturais, perdas econômicas, materiais, infraestrutura e de vidas humanas (FEIZIZADEH; BLASCHKE, 2012).

Nas cidades latino-americanas e, consequentemente, no Brasil, o fator é agravado pelo processo de desenvolvimento passado nas últimas décadas e, crescimento urbano decorrente (SMYTH; ROYLE, 2000; LOPES, 2008; ANGEOLETTO et al., 2019; RUMBLE et al., 2019). Nesse contexto, a significativa concentração populacional e sua demanda por moradias acarretam a ocupação e conformação de assentamentos morfologicamente aleatórios, oriundos das necessidades prementes pela busca de acomodação e posse de terra (DAI; LEE; NGAI, 2002; FERNANDES et al., 2004; SMYTH; ROYLE, 2000; XU et al., 2011). Somados a isso, a especulação imobiliária, pobreza, posse ilegal da terra, carência de infraestrutura, ausência de planejamento e ineficiência de gestão urbana são agentes que contribuem para agravar a situação. Em decorrência disso, há a ocupação de áreas impróprias, como relevo íngreme e com declividades acentuadas, configurando um cenário de drásticas interferências ambientais.

A intensificação da instabilidade geomorfológica, fragilizada pela quantidade expressiva de assentamentos, é potencializada pela realização indiscriminada de escavações, recortes e aterros. Para tal, áreas são desmatadas para dar lugar à implantação de ruas e vielas, e a construção de edificações, contribuindo expressivamente para a ocorrência de deslizamentos. 
De acordo com Dai, Lee e Ngai (2002) os deslizamentos são fenômenos repletos de incertezas, desde o seu surgimento, ao desencadeamento e proporções. Entretanto, pesquisas e métodos de análise da vulnerabilidade física devem ser mitigados para reduzir essas incertezas e os possíveis múltiplos perigos. É indispensável o conhecimento das trocas entre homem e ambiente, sobretudo, a compreensão das interações dos elementos humanos, físicos e biológicos de forma integrada.

Entre os instrumentos metodológicos e técnicos no auxílio ao planejamento e ordenamento territorial, com vistas à orientação e prevenção de desastres, há o uso de ferramentas de coleta e tomada de decisão no Sistema de Informações Geográficas (SIG), vinculado às técnicas de geoprocessamento, e o emprego de Análises de Decisão Multicritério (MCDA).

Dessa forma, são trazidos aqui alguns conceitos e métodos vinculados ao SIG e MCDA, como aporte teórico à análise territorial da qualidade ambiental para identificação de áreas com fragilidades a desmoronamentos.

\section{SIG E MCDA NA AVALIAÇÃO DE PROBLEMAS AMBIENTAIS}

De acordo com diversos autores (WESTEN, 2008; VASILJEVIC et al., 2012), o SIG é uma poderosa ferramenta de modelamento espacial, útil para a estimativa de vulnerabilidades ambientais. Uma vez que a ocorrência de desmoronamentos implica em um processo complexo que envolve inúmeras variáveis e critérios, este possibilita trabalhar com um grande volume de dados e de diversos formatos e fontes. De maneira coerente, é permitida a confrontação de inúmeros fatores e variáveis determinísticas das condições físicas, caracterizando o menor ou maior grau de instabilidade ambiental. Vasiljevic et al. (2012), Dai et al. (2001), Dai, Lee e Ngai (2002) e Zhang et al. (2012) destacam sua importância para a análise do uso urbano, pois trata-se de uma ferramenta de trabalho que interage num vasto campo de questões físicas e sociais inerentes a cidade, simulando cenários em dados e medidas criteriosas.

A MCDA é composta por um conjunto de elementos para a tomada de decisão, que garantem o aperfeiçoamento na definição de importância dos critérios envolvidos na construção de mapeamentos de vulnerabilidade ambiental (VASILJEVIC et al., 2012). Através de métodos indiretos, são introduzidas e valoradas diferentes variáveis, hierarquizadas através de pesos em relação ao contexto, conforme uma árvore de decisão (KANNAN et al., 2012). Resumindo, de acordo com Feizizadeh e Blaschke (2012) e Hill et al. (2005), a análise de decisão multicritério apresenta-se como um processo de combinações e transformações de dados geográficos e de juízos de valor, articulados através de inúmeros algoritmos de concepção que flexibilizam o fornecimento de informações indispensáveis na definição e priorização de detecção de áreas impróprias para a ocupação, em menor ou maior grau. Assim, sendo significativa peça como instrumento de planejamento das cidades. 


\section{ÁREA DE ESTUDO}

Santa Maria possui uma área de $1.781,757 \mathrm{~km}^{2}$ e população estimada de 278.445 , com densidade demográfica de 145,98 hab./ km² (IBGE, 2019), o que a caracteriza como cidade média. No caso, importante polo regional na região central do estado do Rio Grande do Sul (Fig. 1).

Por estar situada no limiar do Rebordo do Planalto Central, conta com uma grande variabilidade paisagística caracterizada por dois biomas, o Pampa e a Mata Atlântica. Ao Sul têm-se os campos, os quais abrigam o Aquífero Guarani. Ao Norte, um relevo acidentado, detentor dos resquícios da floresta estacional decidual, com formação florestal de extenso estrato arbóreo emergente (LÖBLER; SCCOTI; WERLANG, 2015).

Figura 1: Localização de Santa Maria e da área de estudo - perímetro urbano.

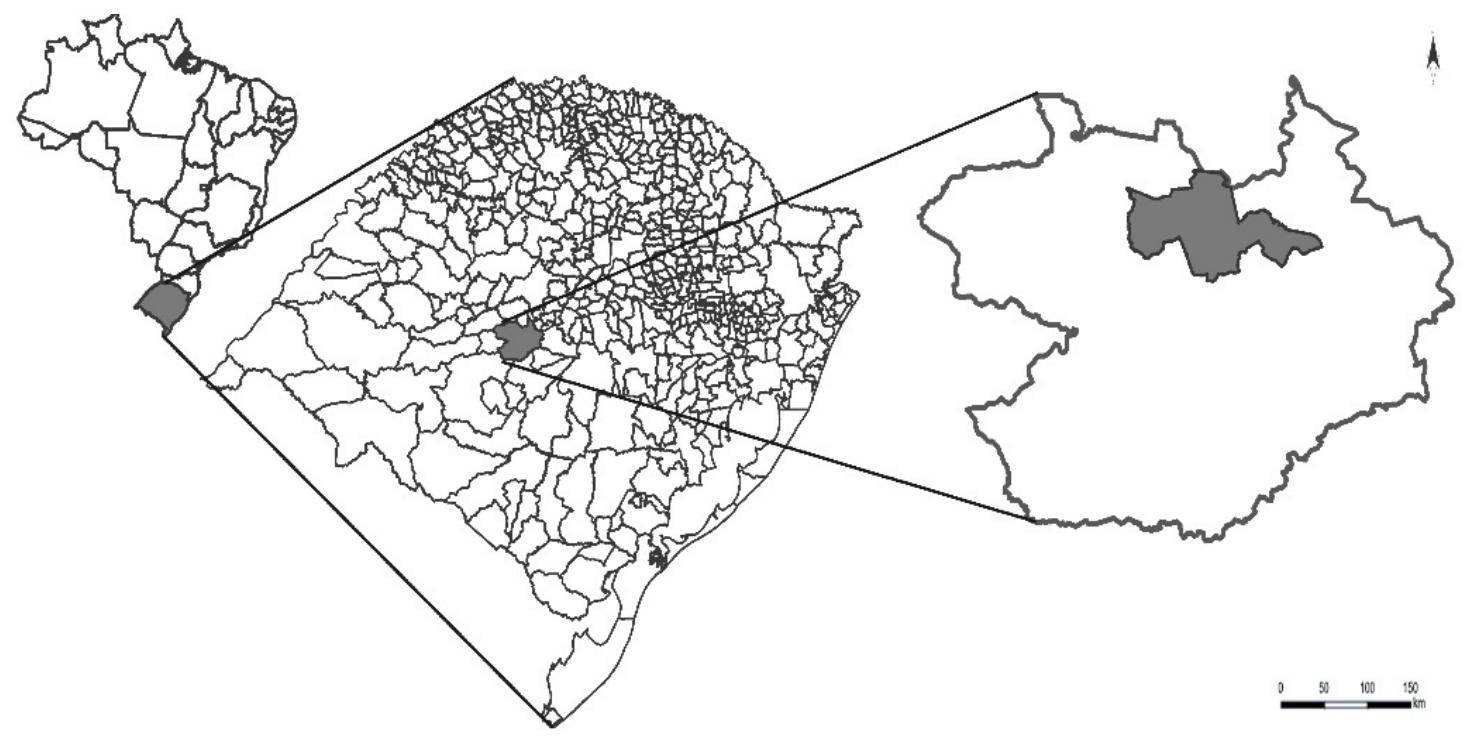

Fonte: IBGE, 2015.

Essas áreas estão sofrendo pressões decorrentes do crescimento urbano, com intensa demanda de ocupação de terras num processo que ameaça a integridade física da paisagem e responsável pelo agravamento de situações emergentes de perigos relacionadas a desastres ambientais.

Ainda que o meio ambiente seja um sistema complexo marcado pela dinâmica de sucessivas mudanças (VICENTE; PEREZ FILHO, 2003), as ações antrópicas no perímetro urbano de Santa Maria caracterizam-se pela urbanização de sítios inapropriados, como nas imediações e sobre os morros e encostas de excessiva declividade.

\section{MATERIAIS E MÉTODOS}

Além de informaç̃oes obtidas em laboratórios de pesquisas vinculados à Universidade Federal de Santa Maria (UFSM), uma das principais fontes documentais foram os órgãos 
vinculados ao município, como a Secretaria de Planejamento Urbano - Escritório da Cidade, que disponibilizou imagens aéreas do perímetro urbano e arquivos em formato shapefile.

De posse dos dados da área de estudo, seguiu-se com a construção de um sistema de hierarquia, sistematizando os diferentes dados, os estágios de análise, processos e os respectivos resultados. Aspectos como geologia, geomorfologia e usos da terra foram inventariados, por constituírem fatores determinantes para o estabelecimento da vulnerabilidade ambiental a deslizamentos conforme Chen et al. (2010; 2011), Kannan et al. (2012) e Westen et al. (2008).

A manipulação e definição dos parâmetros de hipsometria, declividade e tipos de solo foram processados no software ArcGIS 10.2, desenvolvendo-se na base cartográfica na escala de trabalho de 1:50.000, a qual segundo Santos et al. (2010) atendem ao propósito de levantamentos de campo e provem informações adequadas para elaboração de inventários e zoneamentos. O uso do solo do levantado através de fotointerpretação de uma imagem de 2009 de satélite Quickbird ortorretificada, de alta resolução espacial (pixel de 2,8 x 2,8 metros na faixa multiespectral).

A seguir foram formulados pesos na matriz com a definição de uma escala de comparação em pares estabelecida a partir de juízos de valor. Conseguinte, a definição do autovalor, normalização dos valores dos critérios/pesos e a definição do índice de consistência (compreendido entre 0 e 0,1 para compor-se em uma análise de julgamento aceitável).

A seguir são enumerados e descritos detalhadamente os processos e parâmetros utilizados na construção dos mapeamentos.

\section{CONSTRUÇÃO DO MODELO DE SUSCETIBILIDADE: DEFINIÇÃO DE CLASSES E INTENSIDADE DA FRAGILIDADE AMBIENTAL}

Para a qualificação ambiental da área de estudo, os mapas de hipsometria, declividade, tipos de solo e uso e cobertura da terra foram subdivididos em cinco classes (Tabs. 1-4). Estas, por sua vez, julgadas pela valoração de pesos, com atribuições de 0 a 10, levando em consideração as interferências e impactos que as respectivas classes poderiam contribuir para o cenário de fragilidade ambiental a desmoronamentos. Assim, as classes que gradativamente levam a maiores probabilidades de movimento de terra recebem proporcionalmente maiores notas. 
Tabela 1: Hipsometria x Fragilidade

\begin{tabular}{c|c}
\hline \multicolumn{2}{c}{ HIPSOMETRIA } \\
\hline Classe & Intensidade Fragilidade \\
\hline $0-51 \mathrm{~m}$ & 1 \\
\hline $51,01-93 \mathrm{~m}$ & 2 \\
\hline $93,01-137 \mathrm{~m}$ & 4 \\
\hline $137,01-226 \mathrm{~m}$ & 6 \\
\hline $226,01-400 \mathrm{~m}$ & 10 \\
\hline
\end{tabular}

Fonte: os autores

Tabela 3: Pedologia x Fragilidade

\begin{tabular}{c|c}
\hline \multicolumn{2}{c}{ PEDOLOGIA } \\
\hline Classe & Intensidade Fragilidade \\
\hline Água & 1 \\
\hline Planossolo & 2 \\
\hline Alissolo & 4 \\
\hline Argissolo & 6 \\
\hline Neossolo & 10
\end{tabular}

Fonte: os autores
Tabela 2: Declividade x Fragilidade

\begin{tabular}{c|c}
\hline \multicolumn{2}{|c}{ DECLIVIDADE } \\
\hline Classe & Intensidade Fragilidade \\
\hline$<5 \%$ & 1 \\
\hline $5,01-12 \%$ & 3 \\
\hline $12,01-30 \%$ & 5 \\
\hline $30,01-45 \%$ & 8 \\
\hline$>45 \%$ & 10
\end{tabular}

Fonte: os autores

Tabela 4: Uso do solo x Fragilidade

\begin{tabular}{c|c}
\hline \multicolumn{2}{c}{ USO DO SOLO } \\
\hline Classe & Intensidade Fragilidade \\
\hline Água & 4 \\
\hline Mata & 1 \\
\hline Campo & 2 \\
\hline Urbano & 8 \\
\hline Solo exposto & 8 \\
\hline
\end{tabular}

Fonte: os autores

Os critérios adotados foram baseados no uso de intervalos de classes já consagrados no que se referem aos limites críticos da capacidade de uso/aptidão agrícola, bem como em inúmeros trabalhos e pesquisas adjacentes à pesquisa. A partir da comparação de parâmetros adotados por diferentes autores foram estabelecidas as classes e as suas respectivas notas de 1 a 10, considerando características semelhantes, adaptando-as à realidade do perímetro urbano de Santa Maria.

O trabalho baseou-se em estudos que definem os mapeamentos envolvidos nas confrontações, como uso da terra, tipo de solo e as classes de declividades com suas respectivas valorações. Assim, seguiu-se Lossardo e Lorandi (2010), Santos et al. (2010) para considerar classes de declividades e categorias de níveis de fragilidade - as notas atribuídas às classes de hipsometria e declividade tiveram seus maiores valores conforme a maior elevação e aclives/declives.

Pesquisas de Vasiljevic et al. (2012) igualmente serviram como orientação na delimitação do uso do solo e da instabilidade gerada na dinâmica ambiental a partir das diferentes coberturas.

No tocante às características de resistência de cada tipo de solo, baseadas nas propriedades de desempenho quanto à drenagem, profundidade do horizonte, estrutura e localização em altitudes, seguiu-se Reckziegel et al. (2008). Para determinar a vulnerabilidade de cada tipo de solo consultaram-se também Cruz et al. (2010) e Lossardo e Lorandi (2010).

Como resultado da confrontação de valores definiram-se níveis de estabilidade e instabilidade representativos para a paisagem. A Figura 2 demonstra a classificação de cinco níveis de vulnerabilidade ambiental, adaptando a nomenclatura utilizada por Tricart 
(1977) nos seus estudos dos ambientes naturais e antropizados baseados nos conceitos ecodinâmicos, também referenciados nos trabalhos de Ross (1994) e Santos et al. (2010).

Figura 2: Classificação em cinco níveis de intensidade da fragilidade ambiental.

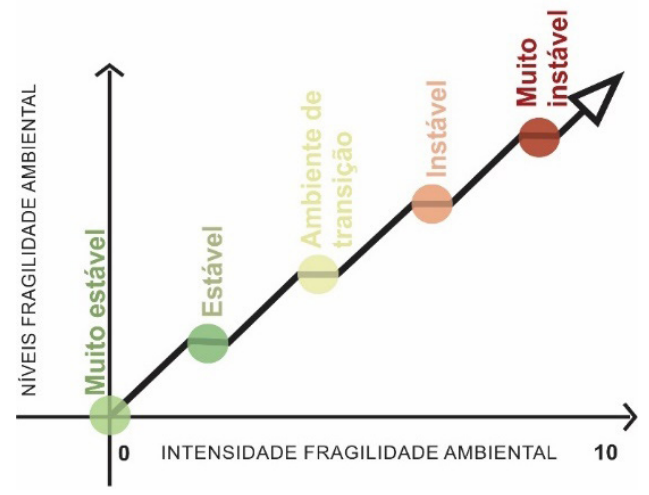

\section{AHP (PROCESSO DE HIERARQUIA ANALÍTICA)}

A etapa seguinte consistiu nas estimativas de vulnerabilidade do meio referentes aos fatores naturais (potencial) e dos riscos ambientais somando as ações do homem (emergente), elaboradas da integração dos mapas básicos. Esse processo foi baseado no modelo morfométrico que parte das classes de declividade como gerenciador e base das análises, proposta por Ross (1994). Segundo Smyth e Royle (2000), na avaliação e identificação de áreas de risco é importante relacionar e estabelecer o quanto as atividades humanas contribuem para o processo. Assim, geraram-se os mapeamentos de vulnerabilidade a fragilidade ambiental potencial (FAP) e a fragilidade ambiental emergente (FAE) conforme fluxograma da Figura 3.

Figura 3: Fluxograma metodológico da preparação de dados para AHP.

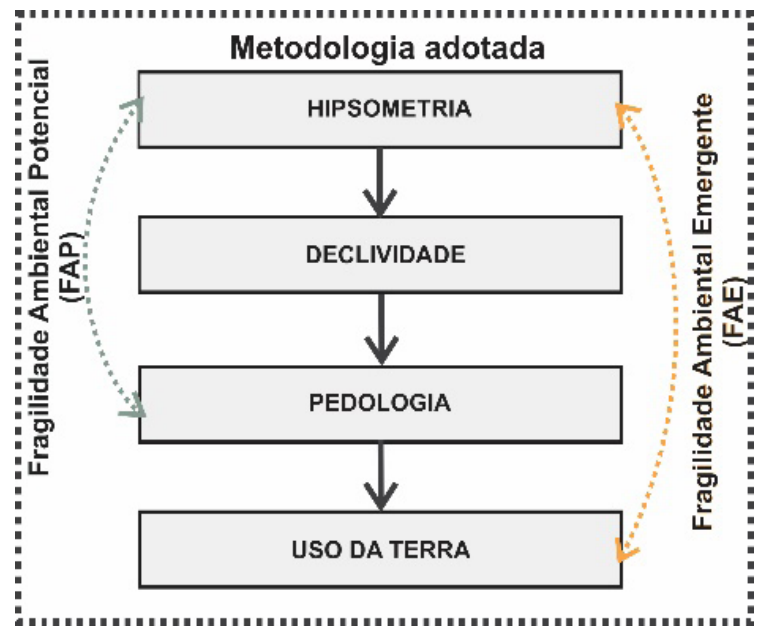

Fonte: adapt. de Ross (1994).

Para a correlação dos mapas foi utilizado o processo de hierarquia analítica (AHP), método proposto por Wharton em 1977 e amplamente empregado na análise de problemas 
envolvendo multicritérios (Fig. 4). Consiste na hierarquização dos elementos que constituem a análise através de pesos, de acordo com seu grau de importância. Trata da simplificação de um complexo sistema em uma matriz de comparações pareadas das variáveis em uma definição linear da hierarquia de importância, numa escala de 1 à 9 (Tab. 5), baseadas na decomposição, julgamento comparativo e síntese de prioridades (PARK et al., 2010; SAATY, 1977; SANTOS et al., 2010; VASILJEVIC et al., 2012 ).

Figura 4: Etapas desenvolvidas no processo de hierarquia analítica AHP.

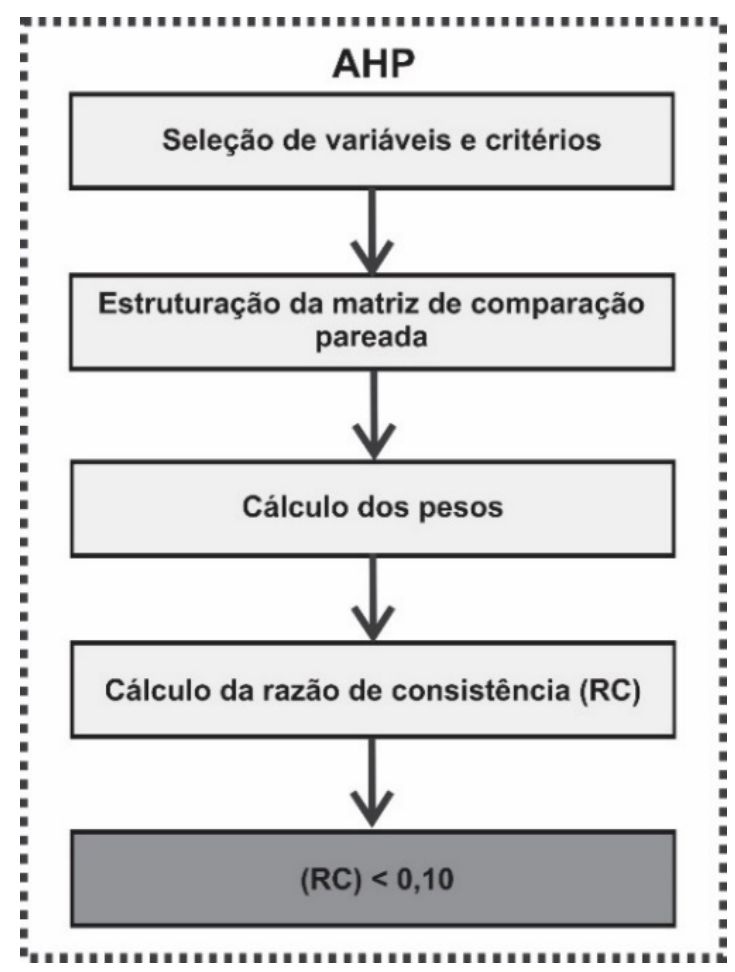

Fonte: os autores.

Tabela 5: Escala de importâncias da AHP

\begin{tabular}{c|c}
\hline PESO & IMPORTÂNCIA \\
\hline $1 / 9$ & Extremamente menos importante que \\
\hline $1 / 7$ & Muito fortemente menos importante que \\
\hline $1 / 5$ & Fortemente menos importante que \\
\hline $1 / 3$ & Moderadamente menos importante que \\
\hline 1 & Igualmente importante a \\
\hline 3 & Moderadamente mais importante que \\
\hline 5 & Fortemente mais importante que \\
\hline 7 & Muito fortemente mais importante que \\
\hline 9 & Extremamente mais importante que \\
\hline $\begin{array}{c}2,4,6 \text { e } 8 \text { valores } \\
\text { intermediários }\end{array}$ & \\
\hline
\end{tabular}

Fonte: adapt. de Saaty e Vargas, 1979. 
O mapeamento de áreas de risco, ao compor-se em uma análise que demanda inúmeras variáveis, envolve intrínsecas relações de critérios tangíveis e intangíveis. Por demandar juízos à valoração, para Vasiljevic et al. (2012), a AHP compõe-se em um método matemático rigoroso, que de modo criterioso hierarquiza a tomada de decisões, simplificando o processo e reduzindo significativamente erros relacionados às etapas de julgamento. Através da análise pareada, as variáveis são submetidas a hipóteses, propiciando chegar a melhor alternativa, o que fornece maior acurácia aos resultados. Ainda, segundo Feizizadeh e Blaschke (2012), comparando diversos métodos de avaliação multicritério aplicados à determinação de susceptibilidades, a AHP apresenta-se como a melhor técnica, pois há maior consistência no mapeamento e validação do modelo. A precisão é sustentada pela possibilidade de verificar a consistência de avaliação da análise, ou seja, averiguar a atribuição coerente dos pesos através do cálculo da Razão de Consistência (RC), que deve estar compreendida entre 0 e 0,10 para satisfazer as simulações (SAATY; VARGAS, 1979). A matriz é determinada a partir das variáveis de estudo, expressa por:

$$
A=\left[\begin{array}{cccc}
a_{11} & a_{12} & \cdots & a_{1 n} \\
a_{21} & a_{22} & \cdots & a_{2 n} \\
\vdots & \vdots & \vdots & a_{3 n} \\
a_{n 1} & a_{n 2} & \cdots & a_{n n}
\end{array}\right]
$$

Trata-se de um instrumento de decisão que permite trabalho quantitativo (parte objetiva) e a atribuição qualitativa (parte subjetiva). Além disso, a AHP permite englobar na análise física ambiental, componentes socioeconômicos nas confrontações, configurando-se em importante ferramenta na gestão e planejamento urbano ZHANG et al. (2012).

Portanto, conforme as etapas e atribuições das classes da Figura 3, foram construídas as matrizes de comparação pareada e as correlações aplicando-se o procedimento técnicooperacional de álgebra de mapas do ArcGIS $10.2 \mathrm{em}$ análises espaciais. Este se configura na elaboração de uma equação de análise simultânea de todos os mapas e suas variáveis, bem como seu grau de importância no contexto, isto é, a sua valoração (peso) em relação aos demais temas (Equação 5, Equação 6 e Equação 7), estabelecidos a partir dos resultados obtidos da operacionalização e da verificação dos pesos estatísticos oriundos da AHP (Equação 2, Equação 3, Equação 4 e Equação 5).

Para a determinação das escalas de importâncias (pesos) adaptou-se para Santa Maria as proposições de Cruz et al. (2010), Gomes et al. (2004); Lossardo e Lorandi (2010), Park et al. (2010), Ross (1994), Santos et al. (2010), Spörl e Ross (2004). Entretanto, as classes mapeadas de declividade e de uso do solo foram ponderadas, pois ao trabalhar-se com os pressupostos adotados por Ross (1994), o relevo é fator determinante para a FAP e, quando se trata da FAE, junto da declividade, é preponderante o uso do solo.

A primeira análise relacionou os mapas de hipsometria, declividade e pedologia, compondo a fragilidade ambiental potencial - FAP (Tab. 6). Foram determinados os valores de importância e calculados os pesos estatísticos, oriundos da razão do somatório de cada variável pela sua totalidade. Posteriormente, realizada a média aritmética, chegando-se ao valor do peso final (), conforme Tabela 7. 
Tabela 6: Matriz de comparação da Fragilidade Ambiental Potencial - FAP.

\begin{tabular}{|c|c|c|c|}
\hline VARIÁVEIS & Hipsometria & Pedologia & Declividade \\
\hline Hipsometria & 1 & $1 / 5$ & $1 / 8$ \\
\hline Pedologia & 5 & 1 & $1 / 3$ \\
\hline Declividade & 8 & 3 & 1 \\
\hline
\end{tabular}

Fonte: os autores.

Tabela 7:Pesos estatísticos das variáveis de FAP.

\begin{tabular}{c|c|c|c|c}
\hline VARIÁVEIS & Hipsometria & Pedologia & Declividade & $\begin{array}{c}\text { Pesos } \\
\text { () }\end{array}$ \\
\hline Hipsometria & 0,0714 & 0,0476 & 0,0857 & 0,0683 \\
\hline Pedologia & 0,3571 & 0,2381 & 0,2286 & 0,2746 \\
\hline Declividade & 0,5714 & 0,7143 & 0,6857 & 0,6571 \\
\hline
\end{tabular}

Fonte: os autores.

Após definição dos pesos, foi feita a avaliação quanto à veracidade das atribuições através do cálculo de razão de consistência (RC).

$$
R C=I C \mid I R
$$

Onde, $R C$ é a razão de consistência, $I R$ é o índice aleatório, pré-determinado de acordo com a ordem da matriz (n), cujo valor é baseado em Saaty (1987) conforme Tabela 8 , onde para $n=3, I R=0,58$.

Tabela 8: Valores do índice aleatório (IR)

\begin{tabular}{c|c|c|c|c|c|c|c|c}
\hline $\mathrm{N}^{\circ}$ & 3 & 4 & 5 & 6 & 7 & 8 & 9 & 10 \\
\hline $\mathrm{IR}$ & 0,58 & 0,90 & 1,12 & 1,24 & 1,32 & 1,41 & 1,45 & 1,51 \\
\hline
\end{tabular}

Fonte: os autores.

O IC é o índice de consistência. Este determinado por:

$I C=\left(\lambda_{\max }-n\right) /(n-1)$

Onde $n$ é o número de variáveis e é o autovetor, calculado pela seguinte equação:

$$
\lambda_{\max }=\frac{1}{n} \sum_{i=1}^{n} \frac{[A w]_{i}}{w_{i}}
$$

Onde é a matriz resultante do produto da matriz de comparação pareada pelo que são os pesos calculados. 


$$
A w=\left[\begin{array}{cccc}
a_{11} & a_{12} & \cdots & a_{1 n} \\
a_{21} & a_{22} & \cdots & a_{2 n} \\
\vdots & \vdots & \vdots & a_{3 n} \\
a_{n 1} & a_{n 2} & \cdots & a_{n n}
\end{array}\right] \times\left[\begin{array}{c}
w_{11} \\
w_{21} \\
\vdots \\
w_{n 1}
\end{array}\right]
$$

Assim, tem-se valor de $\mathrm{RC}=0.0383$ atendendo ao requisito, compatibilizando os graus de importância e, consequentemente, os pesos atribuídos a cada mapa-base.

Foram operacionalizadas as confrontações para determinação da fragilidade ambiental potencial (FAP) efetuando o seguinte processo:

$\mathrm{FAP}=$ hipso $* 0,0683+$ pedol $* 0,2746+$ decliv $^{*} 0,6571$

Posteriormente foi definida a avaliação de fragilidade ambiental emergente onde foram confrontados o mapa de hipsometria, pedologia, declividade e uso do solo (Tabs. 9 e 10).

Tabela 9: Matriz de comparação da Fragilidade Ambiental Emergente - FAE.

\begin{tabular}{c|c|c|c|c}
\hline VARIÁVEIS & Hipsometria & Pedologia & Declividade & Uso do solo \\
\hline Hipsometria & 1 & $1 / 4$ & $1 / 8$ & $1 / 9$ \\
\hline Pedologia & 4 & 1 & $1 / 3$ & $1 / 5$ \\
\hline Declividade & 8 & 3 & 1 & $1 / 3$ \\
\hline Uso do solo & 9 & 5 & 3 & 1 \\
\hline
\end{tabular}

Fonte: os autores.

Tabela 10: Pesos estatísticos das variáveis da FAE.

\begin{tabular}{c|c|c|c|c|c}
\hline VARIÁVEIS & Hipsometria & Pedologia & Declividade & Uso do solo & Pesos () \\
\hline Hipsometria & 0,0455 & 0,0270 & 0,0280 & 0,0676 & 0,0420 \\
\hline Pedologia & 0,1818 & 0,1081 & 0,0748 & 0,1216 & 0,1216 \\
\hline Declividade & 0,3636 & 0,3243 & 0,2243 & 0,2027 & 0,2787 \\
\hline Uso do solo & 0,4091 & 0,5405 & 0,6729 & 0,6081 & 0,5577 \\
\hline
\end{tabular}

Fonte: os autores.

Seguindo os procedimentos anteriores, foi definido o IR (índice aleatório), a partir da ordem da matriz $n=4$, baseado em (SAATY, 1987). Logo IR=0,90. Como resultado, obteve-se $R C=0,0919$, atendendo ao requisito $<0,10$, concluindo-se que os pesos definidos são aceitáveis.

A análise final constitui da integração das variáveis a partir da álgebra de mapas, determinando a fragilidade ambiental emergente executando a seguinte equação:

$\mathrm{FAE}=$ hipso $^{*} 0,0420+$ pedol $^{*} 0,1216+$ decliv $^{*} 0,2787+$ uso da terra*0,5577 


\section{RESULTADOS}

\section{CARACTERÍSTICAS FÍSICAS DA ÁREA DE ESTUDO}

\section{HIPSOMETRIA}

De acordo com Pereira et al. (1989) e Maciel Filho (1990), Santa Maria situa-se em três grandes unidades de relevo, com morros testemunhos isolados no sentido centro-sul, resultantes da resistência dos resíduos decorrentes do processo de erosão das montanhas, o que ocasiona variação abrupta de altitudes (Tab. 11).

Tabela 11: Unidades de relevo e suas características.

\begin{tabular}{c|c}
\hline \multicolumn{2}{c}{ UNIDADES DE RELEVO } \\
\hline $\begin{array}{c}\text { Topo de } \\
\text { planalto }\end{array}$ & $\begin{array}{c}\text { Localiza-se a norte da área de estudo; constam as maiores altitudes da cidade, podendo atingir } \\
\text { perto de } 400 \mathrm{~m} .\end{array}$ \\
\hline $\begin{array}{c}\text { Rebordo do } \\
\text { planalto }\end{array}$ & $\begin{array}{c}\text { Ambiente de transição entre o Planalto e a Depressão Central, sendo característicos os vales e } \\
\text { morros. }\end{array}$ \\
\hline $\begin{array}{c}\text { Depressão } \\
\text { Central }\end{array}$ & $\begin{array}{c}\text { Abrange a maior parte do perímetro urbano, com níveis altimétricos baixos e pouco variáveis, } \\
\text { entre } 0 \text { a } 100 \mathrm{~m} \text {, expressos nas suas colinas e formação de banhados. }\end{array}$ \\
\hline
\end{tabular}

Fonte: os autores.

No mapa hipsométrico (Fig. 5), as cotas altimétricas estão compreendidas entre 51 e $400 \mathrm{~m}$, mas a quase totalidade do perímetro urbano está situado em altitudes que vão de 51,1-137m (Tab. 12).

Figura 5: Variação altitudinal do relevo na área urbana de Santa Maria, RS.

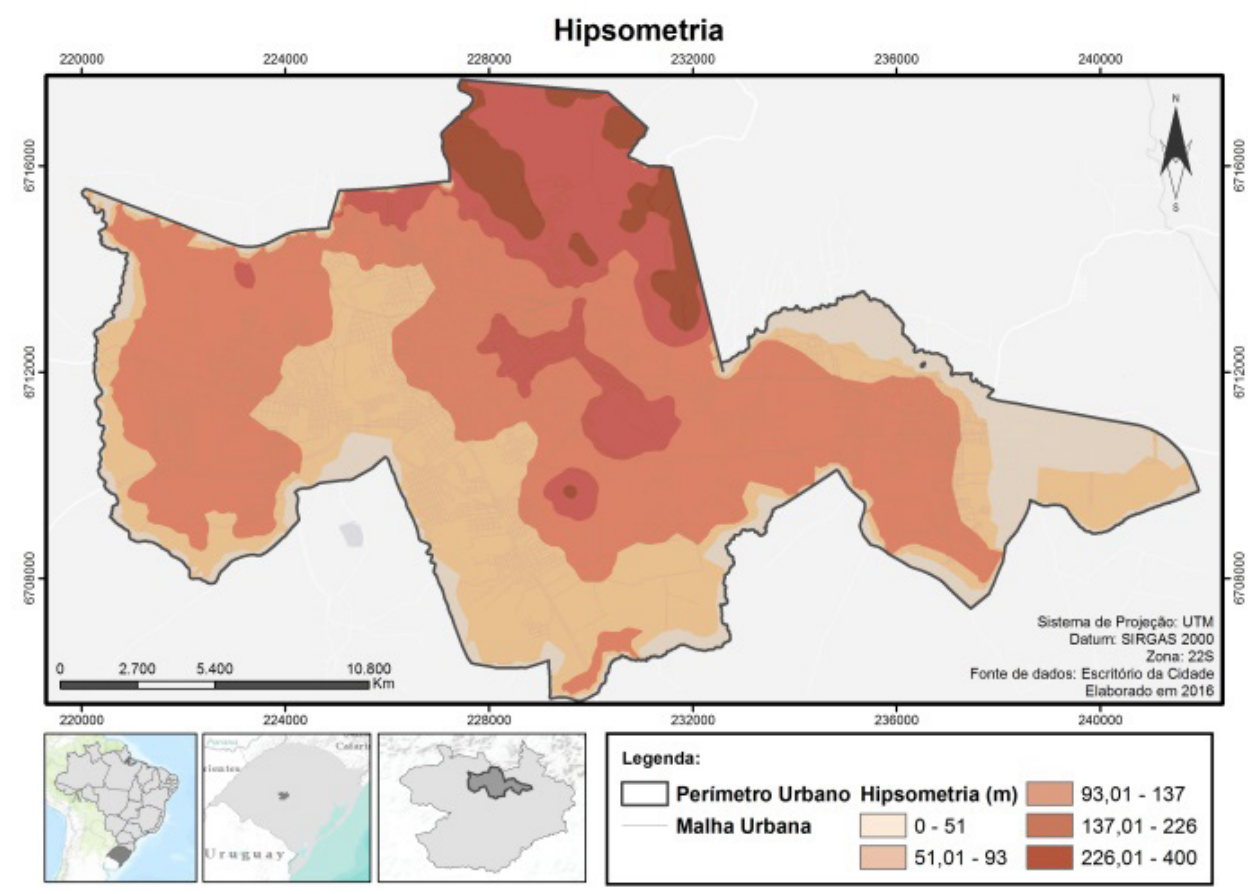

Fonte: os autores. 
Tabela 12: Áreas ocupadas pelas classes hipsométricas na área de estudo.

\begin{tabular}{c|c|c}
\hline Altura $(\mathbf{m})$ & Área $\left(\mathrm{Km}^{2}\right)$ & Porcentagem \\
\hline $0-51$ & 14,08 & 11,21 \\
\hline $51,01-93$ & 34,31 & 27,31 \\
\hline $93,01-137$ & 55,71 & 44,35 \\
\hline $137,01-226$ & 16,03 & 12,76 \\
\hline $226,01-400$ & 5,49 & 4,37 \\
\hline
\end{tabular}

Fonte: os autores.

\section{DECLIVIDADE}

O mapeamento da declividade levou em consideração a classificação de condicionantes físicas e legais na implicação de uma área urbana, rural e de extrativismo vegetal. Baseado em De Biasi (1992), seguindo critérios de qualificação, limites de uso e o Código Florestal brasileiro (Tab. 13), a clinografia do perímetro urbano foi dividida em cinco classes (Tab. 14).

Tabela 13: Cassificação de declividades empregada.

\begin{tabular}{|c|c|c|}
\hline CLASSES & RELEVO & CARACTERÍSTICAS DE USO \\
\hline$<5 \%$ & Plano & urbano ou rural, exceto vales fluviais \\
\hline $5,1-12 \%$ & Moderadamente ondulado & Limite máximo para agricultura mecanizada \\
\hline $12,1-30 \%$ & Ondulado & Linear para urbanização sem restrições legais \\
\hline $30,1-45 \%$ & Fortemente ondulado & $\begin{array}{l}\text { Limite máximo para corte raso de vegetação, } \\
\text { concedido se estiver estruturado por cobertura } \\
\text { florestal (Código Florestal) }\end{array}$ \\
\hline$>45 \%$ & Montanhoso & Proibido corte de vegetação florestal \\
\hline
\end{tabular}

Fonte: adapt. de De Biasi, 1996.

O mapa de declividade (Fig. 6) mostra que o perímetro urbano situa-se consideravelmente em locais com inclinações inferiores a 5\% - cerca de $60 \%$ do recorte de estudo. O intervalo de inclinação compreendido entre 5,01-12\%, ocupa aproximadamente $23 \%$ da área, caracterizada por relevo moderadamente ondulado. Algumas áreas circundantes ao perímetro apresentam características de relevo ondulado, e uma pequena parcela conforma-se em relevo fortemente ondulado e montanhoso, não passando de 4,5\% da área. Essas declividades acentuadas, compreendendo as classes clinográficas superiores a 30\%, estão em consonância com as maiores altitudes, o que implicam, de antemão, em impedimentos de uso, conforme já mencionado. 
Figura 6: Mapa de declividades do perímetro urbano de Santa Maria, RS.

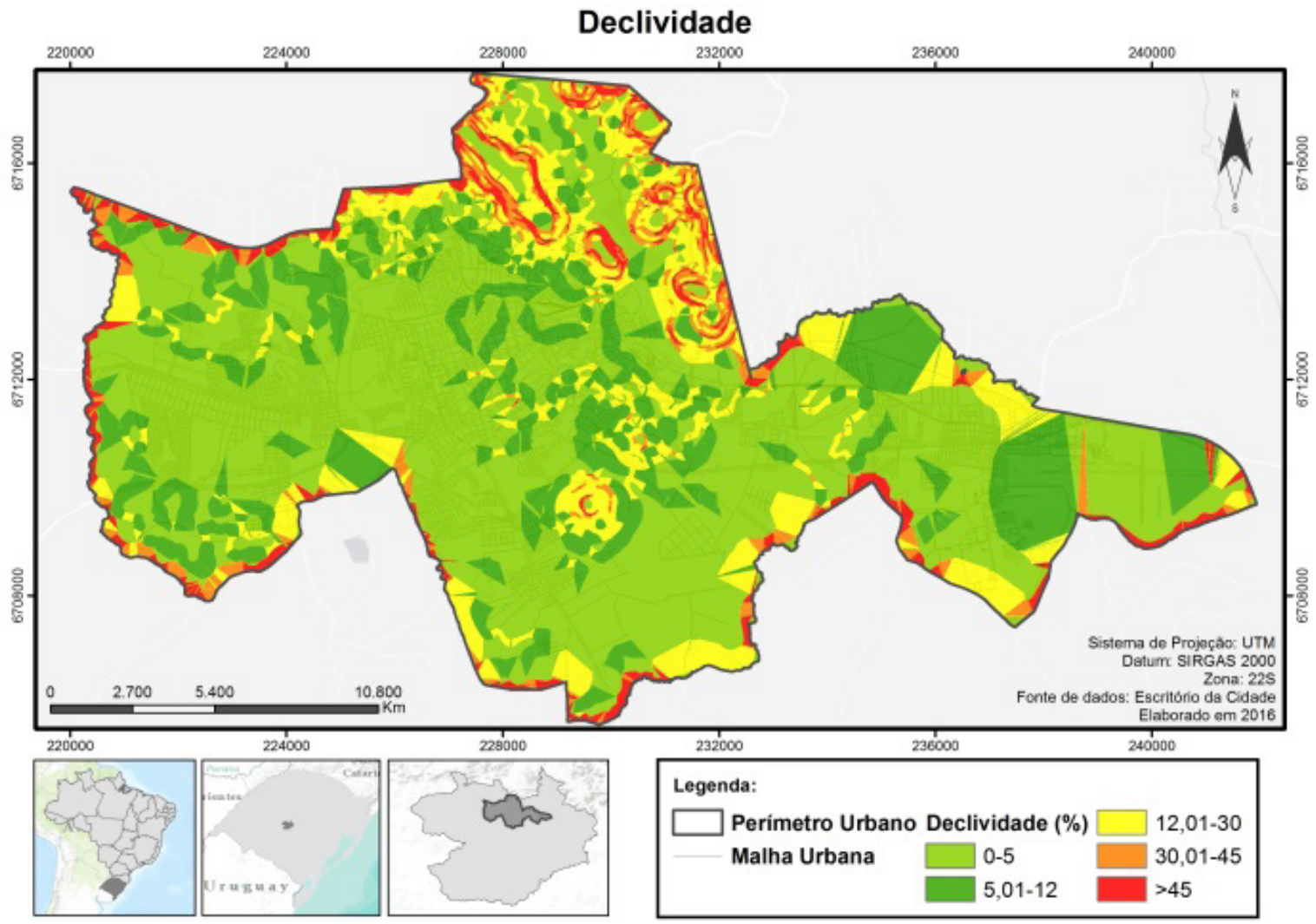

Fonte: os autores.

Tabela 14: Área ocupada pelas classes de declividade na área de estudo.

\begin{tabular}{c|c|c}
\hline DECLIVIDADE & ÁREA $\left(\mathrm{Km}^{2}\right)$ & PORCENTAGEM \\
\hline $0-5 \%$ & 76,03 & 60,52 \\
\hline $5,01-12 \%$ & 29,09 & 23,16 \\
\hline $12,01-30 \%$ & 14,91 & 11,87 \\
\hline $30,01-45 \%$ & 3,71 & 2,95 \\
\hline$>45 \%$ & 1,88 & 1,50 \\
\hline
\end{tabular}

Fonte: os autores.

\section{TIPOS DE SOLO}

De acordo com dados do Departamento de Solos da Universidade Federal de Santa Maria, na área ocorrem quatro tipos de solo principais: Planossolos, Alissolos, Argissolos e Neossolos (Tab. 15). 
Tabela 15: Área ocupada pelos tipos de solo nas áreas de estudo.

\begin{tabular}{c|c|c|}
\hline TIPO DE SOLO & ÁREA $\left(\mathrm{Km}^{2}\right)$ & PORCENTAGEM \\
\hline Água & 0,67 & 0,54 \\
\hline Planossolos & 30,54 & 24,31 \\
\hline Neossolos & 7,47 & 5,95 \\
\hline Argissolos & 30,94 & 24,63 \\
\hline Alissolos & 55,99 & 44,57 \\
\hline
\end{tabular}

Fonte: os autores.

É possível constatar, a partir da Figura 7 que significativa parcela do perímetro urbano está localizada sobre Planossolos (24\%) e Alissolos (45\%), caracteristicamente presentes em altitudes máximas de $137 \mathrm{~m}$. Já Argissolos normalmente estão associados a relevos fortemente ondulados e montanhosos. Da mesma forma Neossolos, que ocorrem em relevos movimentados.

Figura 7: Mapa dos tipos de solo e identificação dos corpos d'água no perímetro urbano de Santa Maria, RS.

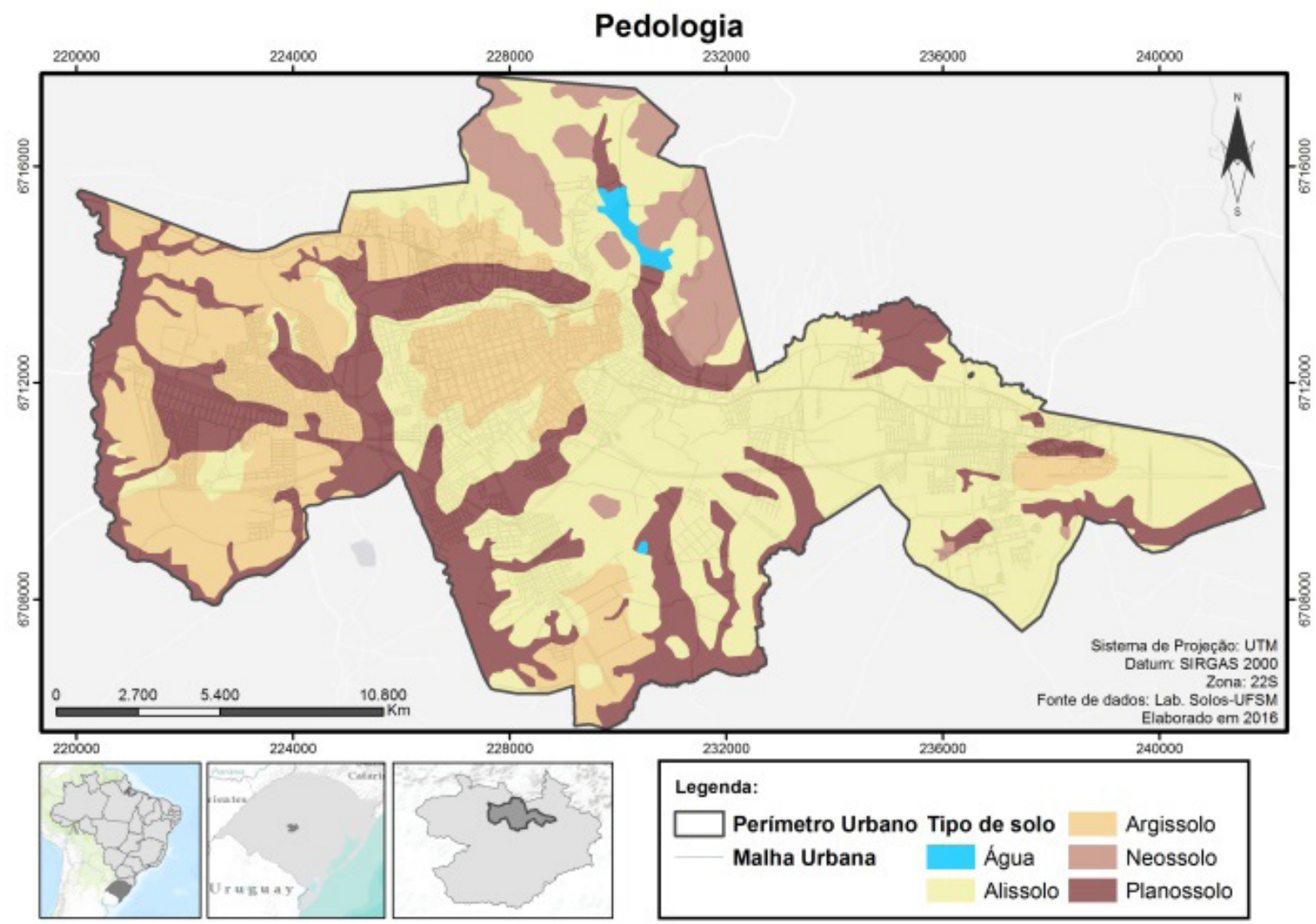

Fonte: os autores. 


\section{USO DA TERRA}

A divisão e a classificação do uso da terra (Tab. 16) foram fundamentadas nos trabalhos de Cruz et al. (2010), Ross (1994), Pinese Júnior et al. (2008), Lossardo e Lorandi (2010) e Spörl e Ross (2004), uma vez que as pesquisas relacionam a intensidade e desenvolvimento dos processos de desmoronamentos de uma área à intensidade da proteção proporcionada pela cobertura vegetal.

Tabela 16: Critérios de classificação dos usos da terra na área de estudo.

\begin{tabular}{c}
\hline CLASSES DE USO DO SOLO \\
\hline Corpos d'água: compostos pela formação natural de banhados/lagos e artificiais como barragens e açudes \\
\hline Campos: formados pela cobertura vegetal de forração gramínea e de pequeno porte \\
\hline Mata: caracterizada pela cobertura vegetal de maciços florestais naturais e artificiais \\
Solo exposto: referente às áreas cultiváveis, pastos, voçorocas e de uso antrópico não edificável \\
praças e arruamentos
\end{tabular}

Fonte: os autores.

O recorte de estudo apresenta aproximadamente um terço do território urbanizado, com as maiores ocupações nas zonas com altimetria e declividades reduzidas. Entretanto, nota-se a pressão urbana sobre os $19 \%$ do território ocupados por remanescentes da Mata Atlântica nos morros ao norte e no entorno de uma barragem (Fig. 8; Tab. 17). Alvo da especulação imobiliária com a implantação de condomínios de alto padrão, assim como ocupações precárias da população carente, essas tomadas indiscriminadas de território têm levado a redução severa de área naturais, causando danos ao ambiente natural e paisagístico da cidade. Estas ações constituem crime ambiental, uma vez que foram mapeadas pela FEPAM (Fundação Estadual de Proteção Ambiental) e fazem parte da Reserva da Biosfera da Mata Atlântica (RBMA)1, cuja implementação teve o intuito de promover o desenvolvimento sustentável para a região, porém com pouco êxito. A parte restante de áreas verdes localiza-se nas áreas íngremes do Centro-sul, o que impõe barreiras naturais ao avanço urbano.

A cobertura por campo e solo exposto representa cerca de metade do território, mostrando o grande aproveitamento agropecuário na forma de pastagens, lavouras de arroz, soja e milho. Essas culturas, principalmente a sudoeste da cidade, ameaçam a integridade das áreas nativas de campos úmidos nas áreas ripárias e a recarga do Aquífero Guarani. 
Figura 8: Mapa de uso e cobertura da terra no perímetro urbano de Sana Maria, RS.

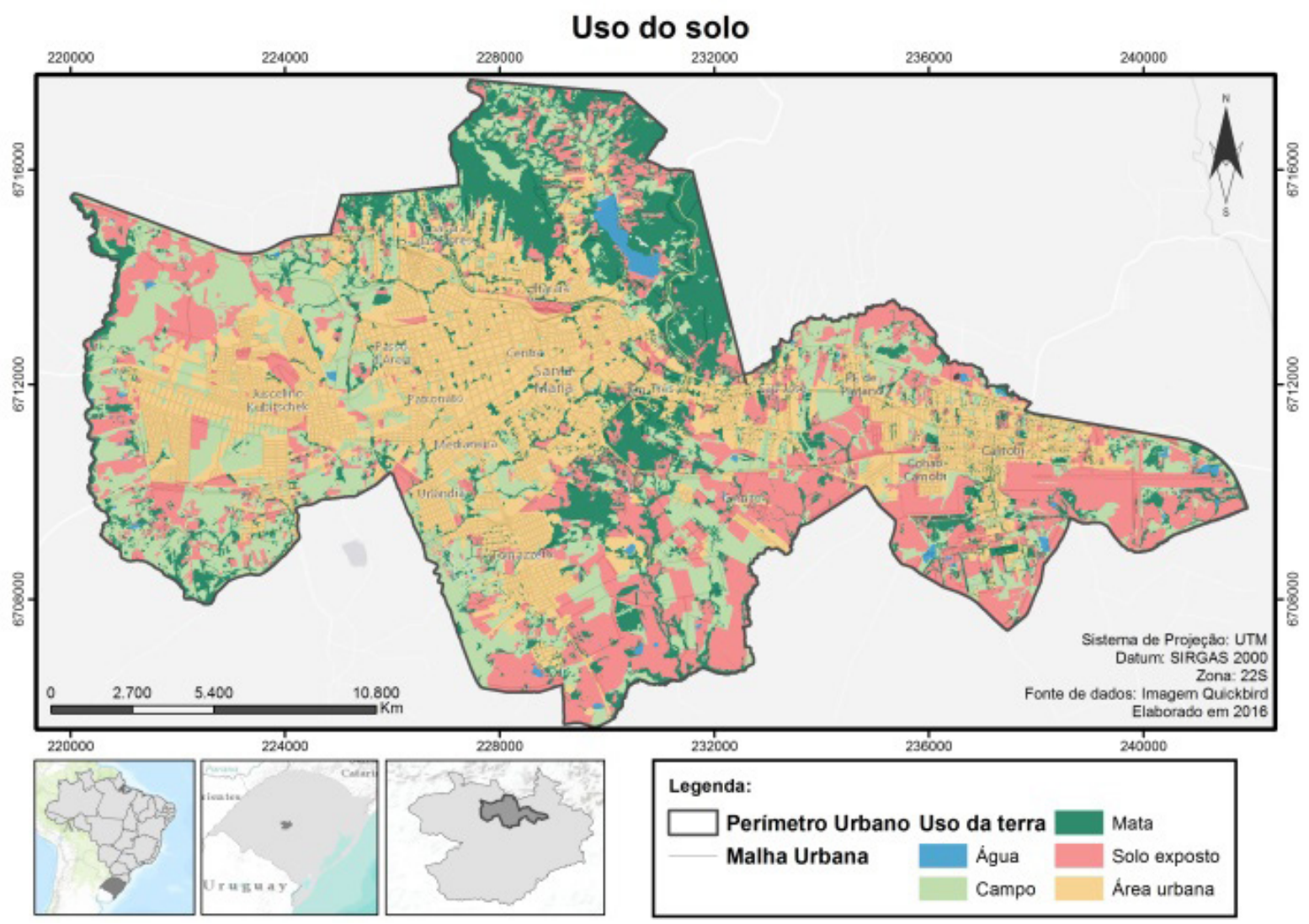

Fonte: os autores.

Tabela 17: Área ocupada pelos usos da terra na área de estudo.

\begin{tabular}{c|c|c}
\hline USO & ÁREA $\left(\mathrm{Km}^{2}\right)$ & PORCENTAGEM \\
\hline Água & 1,20 & 0,96 \\
\hline Campo & 29,39 & 23,40 \\
\hline Mata & 23,72 & 18,88 \\
\hline Solo exposto & 31,74 & 25,27 \\
\hline Urbano & 39,56 & 31,49 \\
\hline
\end{tabular}

Fonte: os autores.

\section{FRAGILIDADE AMBIENTAL POTENCIAL (FAP)}

As cotas altimétricas, classes de declividade e tipos de solo expressam as características do meio, ou seja, as potencialidades e deficiências inerentes ao ambiente natural. Identificouse um território com $78 \%$ das áreas em condições naturais consideradas muito estável a estável (Tab. 18. Fig. 9). Houve a combinação de fatores como baixas altitudes, declividades reduzidas e solos mais resistentes aos processos de movimentos de massa, que garantem a estabilidade. As áreas de transição ocupam 11,88\%, situando-se em locais com altitudes que variam de 137 a $226 \mathrm{~m}$ e declividades que chegam até $30 \%$. Alissolos e Argissolos 
compõem os solos dessa zona e apresentam variação de bem a imperfeitamente drenados, demandando cuidados quanto à erosão quando associados a altas altitudes.

Tabela 18: Área ocupada por áreas de FAP na área e estudo.

\begin{tabular}{c|c|c}
\hline NÍVEL FRAGILIDADE POTENCIAL & ÁREA $\left(\mathrm{Km}^{2}\right)$ & PORCENTAGEM \\
\hline Muito estável & 46,44 & 36,97 \\
\hline Estável & 51,72 & 41,17 \\
\hline Ambiente de transição & 14,92 & 11,88 \\
\hline Instável & 8,31 & 6,61 \\
\hline Muito instável & 4,23 & 3,37 \\
\hline
\end{tabular}

Fonte: os autores.

Figura 9: Fragilidade ambiental potencial (FAP) no perímetro urbano de Santa Maria, RS.

\section{Fragilidade Ambiental Potencial (FAP)}

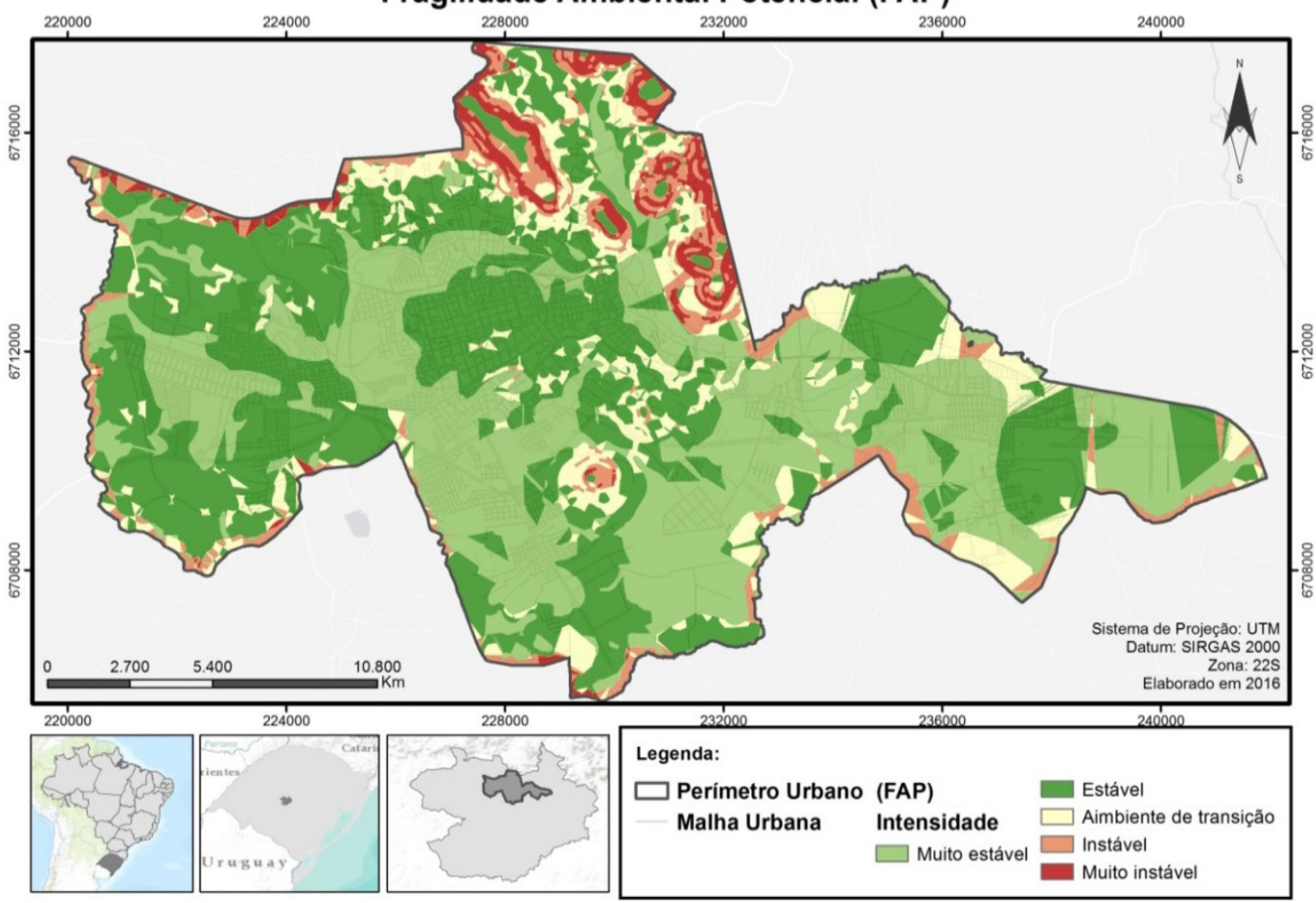

Fonte: os autores.

Já os locais instáveis e muito instáveis representam quase 10\%. São identificados onde os aspectos naturais do meio possuem acentuada declividade e maiores altitudes, bem como onde há ocorrem Neossolos. Caracterizado pela reduzida profundidade efetiva do seu extrato, tem reduzido volume de solo para suportar vegetação, reter a umidade e, consequentemente, possui elevada erodibilidade potencial e pouca capacidade agrícola ou para edificações. 


\section{FRAGILIDADE AMBIENTAL EMERGENTE (FAE)}

Ao incluir o mapeamento de uso da terra, notam-se alterações no panorama geral do perímetro urbano. Áreas antes consideradas muito estáveis e estáveis tornam-se ambientes de transição ou instáveis, compondo cerca de $60 \%$ do total (Tab. 19). As principais alterações configuram-se no sentido do eixo Leste-Oeste, em áreas adjacentes ao núcleo e centro-sul (Figs. 10 e 11). Mudanças das áreas de cultivos e descampados ao sul, e a propulsão do crescimento urbano incentivado pelo Plano Diretor de 2005 na direção Leste-Oeste.

Tabela 19: Área ocupada por áreas de FAE na área de estudo.

\begin{tabular}{c|c|c}
\hline NÍVEL DE FRAGILIDADE EMERGENTE & ÁREA $\left(\mathrm{Km}^{2}\right)$ & PORCENTAGEM \\
\hline Muito estável & 20,04 & 15,95 \\
\hline Estável & 28,98 & 23,07 \\
\hline Ambiente de transição & 58,62 & 46,67 \\
\hline Instável & 17,58 & 13,99 \\
\hline Muito instável & 0,40 & 0,31 \\
\hline
\end{tabular}

Fonte: os autores.

Nesse sentido, áreas centrais no mapeamento FAP consideradas estáveis atingiram níveis de instabilidade pela associação de ocupação urbana a Argissolos que, expostos às ações de uso tem sua estabilidade modificada. A transição pode ser observada na Tabela 20, com o acréscimo de 7\% de áreas consideradas instáveis. Este cenário demanda cuidados por incluir áreas urbanas consolidadas, ou seja, com impermeabilização de extensas superfícies, edificações em altura e, consequentemente, concentração populacional. Os espaços muito estáveis e estáveis sofreram uma redução de 21,01\% e 18,10\% respectivamente, em contraposição ao expressivo aumento de quase 35\% dos ambientes de transição.

Essas alterações nos níveis de estabilidade demandam atenção, sobretudo, quando da existência de malha urbana, responsáveis por gerar modificações nas propriedades físicas dos solos, especialmente Alissolos. Este, por estar estruturado em camadas superficiais, conforme Reckziegel et al. (2008), fica sujeito à erosão com ocorrência de voçorocas. Logo, demanda restrições de uso diante de ações como corte e aterro, muito empregados na construção civil.

A redução de áreas ambientalmente muito instáveis está relacionada à presença de vegetação nos locais naturais mais críticos, ou seja, em áreas de maior altitude, relevo íngreme e solo raso. 
Tabela 20: Valores de transição FAP para FAE na área de estudo.

\begin{tabular}{c|c|c|c|c}
\hline $\begin{array}{c}\text { NÍVEIS } \\
\text { FRAGILIDADE }\end{array}$ & FAP ÁREA $\left.\mathbf{( K m}^{\mathbf{2}}\right)$ & FAE ÁREA $\left.\mathbf{( K m}^{\mathbf{2}}\right)$ & $\begin{array}{c}\text { TRANSIÇÃO FAP PARA } \\
\text { FAE-ÁREA } \mathbf{( \mathbf { K m } ^ { 2 } )}\end{array}$ & $\begin{array}{c}\text { TRANSIÇÃO } \\
\mathbf{( \% )}\end{array}$ \\
\hline Muito estável & 46,44 & 20,04 & $-26,39$ & 21,01 \\
\hline Estável & 51,72 & 28,98 & $-22,74$ & 18,10 \\
\hline $\begin{array}{c}\text { Ambiente de } \\
\text { transição }\end{array}$ & 14,92 & 58,62 & 43,70 & 34,79 \\
\hline Instável & 8,31 & 17,58 & 5 & 7,38 \\
\hline Muito instável & 4,23 & 0,39 & $-3,84$ & 3,06 \\
\hline
\end{tabular}

Fonte: os autores

O mapeamento com as áreas/população residente confeccionado a partir do método de interpolação dos dados referentes aos setores censitários do IBGE (2010) indica que as maiores concentrações populacionais se situam em áreas de transição e instabilidade (Fig. 10), em locais onde anteriormente se julgava estarem em níveis de estabilidade. Uma área com expressivo número de residentes encontra-se à Leste, no Bairro Camobi, que registra os maiores índices de crescimento do município, passando por progressivo processo de urbanização e implantação de infraestrutura. Este crescimento é impulsionado por dois polos regionais, a Universidade Federal de Santa Maria e a Base Aérea.

Figura 10: Densidade de residentes no perímetro urbano de Santa Maria, RS.

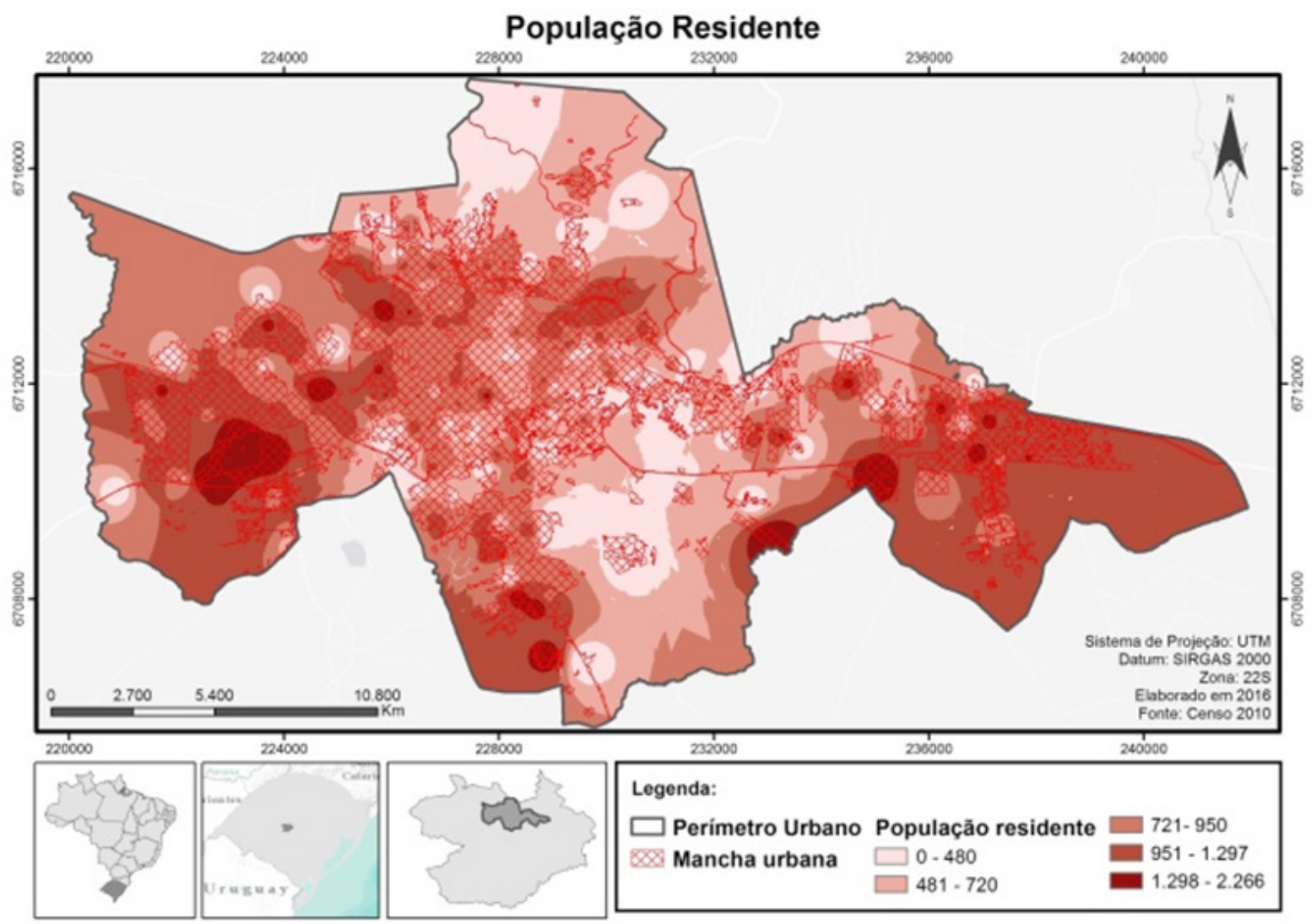

Fonte: os autores. 
Figura 11: Fragilidade ambiental emergente (FAE) no perímetro urbano de Santa Maria, RS.

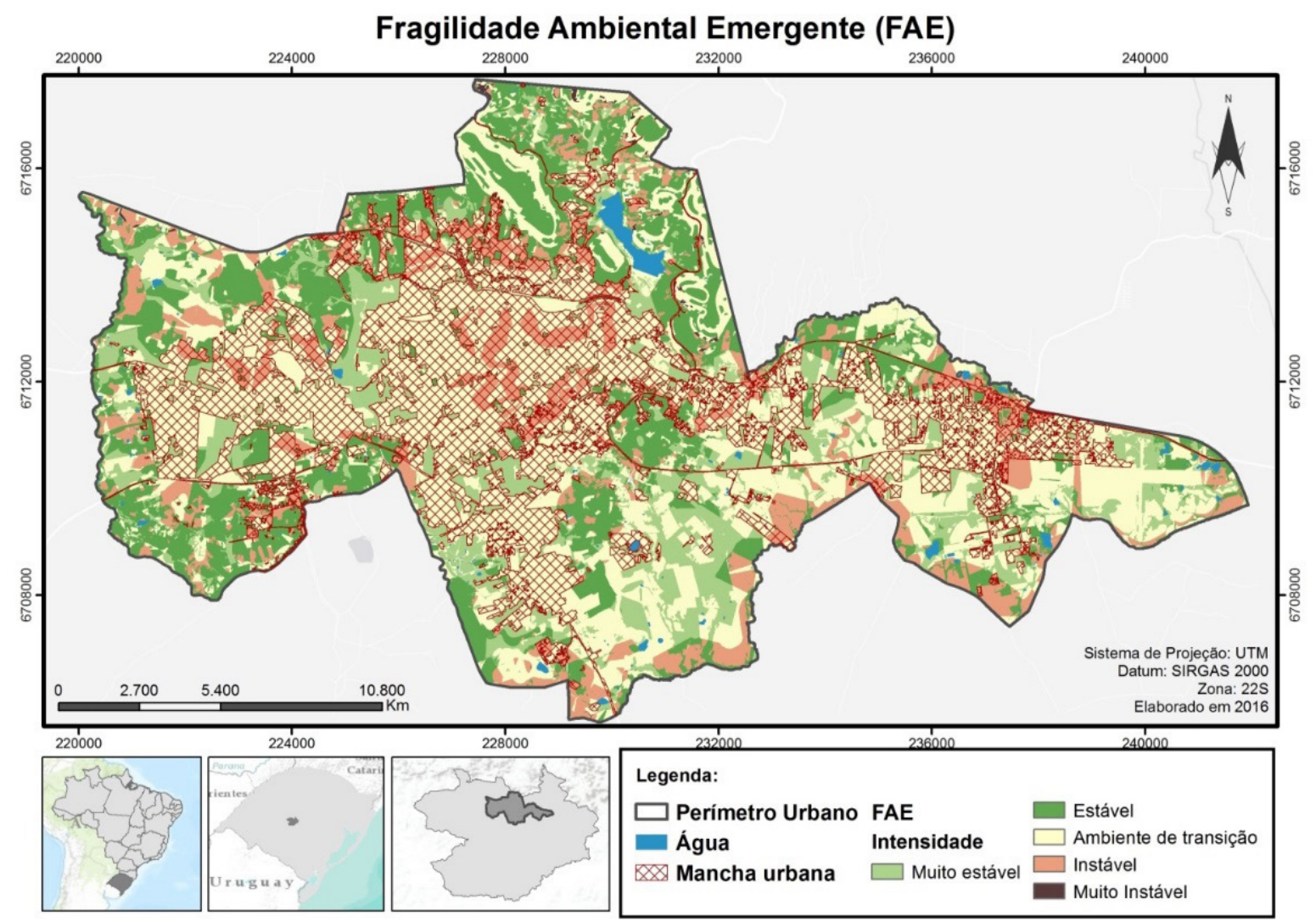

Fonte: os autores.

A Figura 12 mostra o panorama das transições que ocorrem entre FAP e FAE. Visivelmente há uma queda drástica nos níveis de estabilidade, com aproximadamente $49 \mathrm{Km}^{2}$ de redução. Em contrapartida, igualmente com quase $49 \mathrm{Km}^{2}$, os espaços de transição e instabilidade sofreram acréscimo.

Figura 12: Transição FAP para FAE na área de estudo.

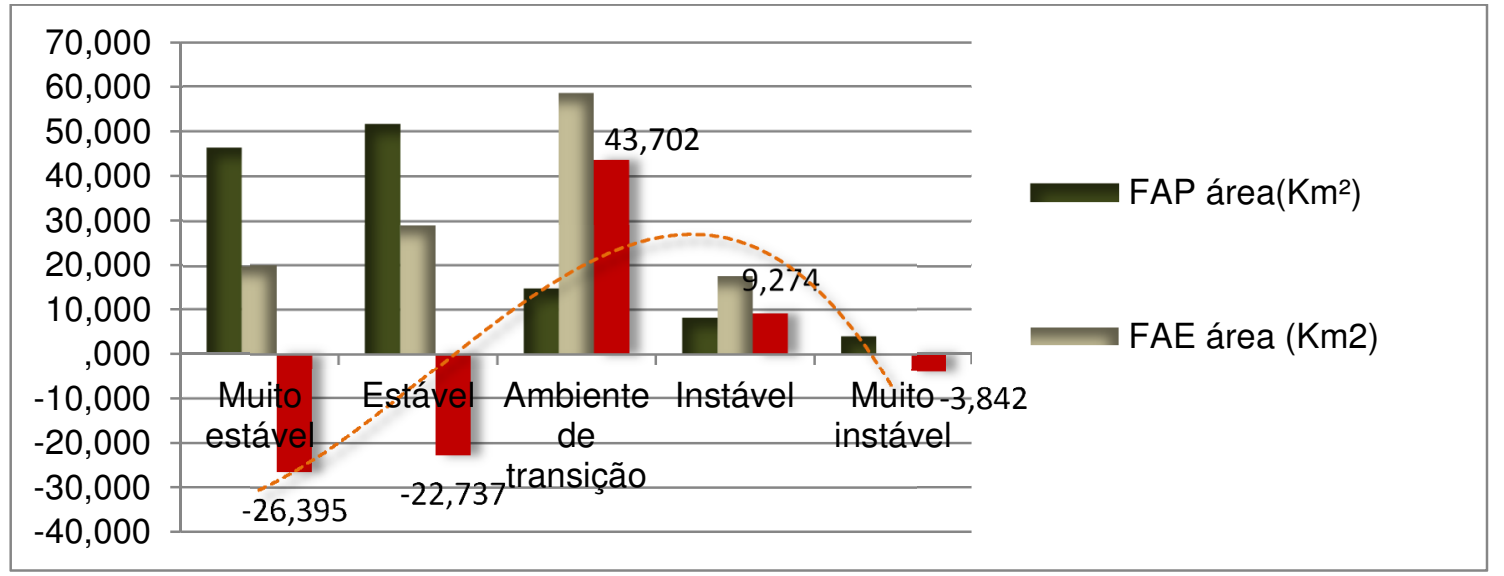

Fonte: os autores. 


\section{CONSIDERAÇÕES FINAIS}

A produção das cartas de fragilidade potencial e emergente de desmoronamentos representa um diagnóstico-síntese qualitativo do perfil ambiental do município. Isso possibilita, de forma concreta e hábil, visualizar precisamente as áreas de risco e, sobretudo, desenvolver um plano diretor municipal que estabeleça quais áreas necessitam de metas preventivas, de seguridade pública, intervenção, reestruturação, recuperação ambiental, e quais as passíveis de crescimento urbano.

Ao fazer um prognóstico da fragilidade emergente, nota-se que a maior parte do perímetro urbano está situado em ambiente de transição. Por conseguinte, isso quer dizer que esse relativo equilíbrio pode ser facilmente desfeito em virtude de intervenções antrópicas e tornar-se um território instável. Diante do conjunto, poucas são as áreas de ambas as instabilidades em que a morfogênese foi modificada, levando a riscos eminentes, não chegando a 15\% do território total do perímetro. Porém medidas cautelares devem ser tomadas, de modo a evitar desastres, estes de grandes impactos em se tratando de espaços urbanos.

Áreas importantes como a mata existente no Topo e Rebordo do Planalto Central devem ser alvo de ações conservacionistas, valorizando o sistema paisagístico do local. Sob um sistema de instrumentos ostensivos, deve-se garantir que esses espaços com a cobertura vegetal continuem proporcionando a estabilidade ambiental, sua função ecológica, estética e paisagística.

Além disso, as áreas alagáveis localizadas a sudoeste também apresentam alto potencial ecológico, pois conformam-se em um ecossistema peculiar bastante biodiverso em espécies da flora e fauna.

Diante disso, tendo em vista que o estudo está estruturado em um sistema de dados detalhados e georreferenciados, projeta-se como apoio à gestão municipal na construção e ocupação do espaço urbano. Trata-se de uma ferramenta importante e necessária à implementação de políticas públicas consonantes aos objetivos dos programas nacionais urbanos para salvaguardar o bem-estar e o patrimônio da população. Nesse sentido, convém garantir o fornecimento de infraestrutura e equipamentos urbanos em áreas adequadas, com aportes tecnológicos e modelos construtivos de baixo impacto ambiental, reduzindo consideravelmente os desastres ambientais e proporcionando a equidade socioespacial.

\section{REFERÊNCIAS}

ANGEOLETTO, F.; FELLOWES, M.D.; ESSI, L. et al. Ecología urbana y planificación: una convergéncia ineludible. Revista Electrônica em Gestāo, Educaçāo e Tecnologia Ambiental, v. 23, (e17), p.1-7, 2019.

CHEN, L.X.; Li, H.; YIN, K.L. et al. Building vulnerability evaluation in landslide deformation phase. Journal of Mountain Science, v. 8, n. 2, p. 286-295, 2011. Disponível em: http://link.springer.com/ article/10.1007\%2Fs11629-011-2101-z. Acesso em: 10 jul. 2019.

CHEN, Yun; YU, Jia; KHAN, Shahbaz. Spatial sensitivity analysis of multi-criteria weights in GIS-based land suitability evaluation. Environmental Modelling \& Software, v. 25, n. 12, p. 1582-1591, 2010. Disponível em: http:/ / www.sciencedirect.com/science/article/pii/S1364815210001842. Acesso em: 10 jul. 2019. 
CRUZ, Lísia M.; PINESE JÚNIOR, José F.; RODRIGUES, Silvio C.. Abordagem cartográfica da fragilidade ambiental na Bacia Hidrográfica do Glória - MG. Revista Brasileira de Cartografia, v. 62, n. 3, p. 505-515, 2010.

DAI, Fuchu; LEE, C.F.; NGAI, Y.Y. Landslide risk assessment and management: an overview. Engineering Geology, v. 64, n. 1, p. 65-87, 2002.

DAI, Fuchu; LEE, C.F.; ZHANG, Xiaohui. GIS-based geo-environmental evaluation for urban land-use planning: a case study. Engineering Geology, v. 61, n. 4, p. 257-271, 2001.

DE BIASI, Mário. A Carta Clinográfica: Os Métodos de representaçãoo e sua Confecção. Geography Rev. do Departmento de Geografia, v.6, p. 46-60, 1992.

FEIZIZADEH, Bakhtiar; BLASCHKE, Thomas. GIS-multicriteria decision analysis for landslide susceptibility mapping: comparing three methods for the Urmia lake basin, Iran. Natural Hazards, v. 65, n. 3, p. 2105-2128, 2012.

FERNANDES, Nelson F.; GOMES, Roberto A.T.; GUIMARÃES, Renato F.; VIEIRA, Bianca C. Topographic controls of landslides in Rio de Janeiro: field evidence and modeling. Catena, v. 55, n. 2, p. 163-181, 2004.

GOMES, Luiz F.A.M.; ARAYA, Marcela C.G.; CARIGNANO, Claudia. Tomada de decisões em cenários complexos: introdução aos métodos discretos do apoio multicritério a decisão. São Paulo: Thomson, 2004.

HILL, Michael J.; BRAATEN, Robert O.; VEITCH, Simon M. et al. Multi-criteria decision analysis in spatial decision support: the ASSESS analytic hierarchy process and the role of quantitative methods and spatially explicit analysis. Environmental Modelling \& Software, v. 20, n. 7, p. 955-976, 2005.

IBGE - Instituto Brasileiro de Geografia e Estatística. Diretoria de Pesquisas - DPE - Coordenação de População e Indicadores Socias - COPIS, 2017. Disponível em: http://cidades.ibge.gov.br/xtras/perfil. php?lang=\&codmun $=431690 \&$ search $=||$ infogr\%E1ficos:-informa $\% E 7 \% F 5 e s-c o m p l e t a s$. Acesso em: 18 fev. 2019.

KANNAN, Maruthu; SARANATHAN, Shanmugavalli E.; ANABALAGAN, Rathinam. Landslide vulnerability mapping using frequency ratio model: a geospatial approach in Bodi-Bodimettu Ghat section, Theni district, Tamil Nadu, India. Arabian Journal of Geosciences, v. 6, n. 8, p. 2901-2913, 2012.

LÖBLER, Carlos A.; SCCOTI, Anderson A.V.; WERLANG, Mauro K. Contribuição à delimitação dos biomas Pampa e Mata Atlântica no município de Santa Maria, RS. Revista Eletrônica em Gestão, Educação e Tecnologia Ambiental v. 19, n. 2, p. 1250-1257, 2015.

LOPES, Juarez R.B. Desenvolvimento e mudança social formação da sociedade urbano-industrial no Brasil. Rio de Janeiro: Centro Edelstein de Pesquisas Sociais, 2008.

LOSSARDO, Luiz F.; LORANDI, Reinaldo. Caracterização das potencialidades e fragilidades ambientais do meio físico de parte do município de Santa Rita do Passa Quatro (SP). Geociências, v. 29, n. 3, p. 389399, 2010.

MACIEL FILHO, Carlos L. Carta Geotécnica de Santa Maria. Santa Maria: Ed. UFSM, 1990.

PARK, Soyoung; JEON, Seongwoo; CHOI, Chuluong. Mapping urban growth probability in South Korea: comparison of frequency ratio, analytic hierarchy process, and logistic regression models and use of the environmental conservation value assessment. Landscape and Ecological Engineering, v. 8, n. 1, p. 17-31, 2010.

PEREIRA, Paulo R.B.; GARCIA NETTO, Luiz da R.; BORIN, Carlos J.A.; SARTORI, M.da G.B. Contribuição à Geografia Física do município de Santa Maria: unidades de paisagem. Geografia Ensino \& Pesquisa, v. 3, p. 37-68, 1989.

PINESE JÚNIOR, José F.; CRUZ, Lísia M.; RODRIGUES, Sílvio C. Monitoramento de erosão laminar em diferentes usos da terra, Uberlândia - MG. Sociedade \& Natureza, v. 20, n. 2, p. 157-175, 2008.

RECKZIEGEL, Bernadete W.; ROBAINA, Luis E. de S.; OLIVEIRA, Edson L. de A. Mapeamento de áreas de risco geomorfológico nas bacias hidrográficas dos arroios Cancela e Sanga do Hospital, Santa Maria-RS. Geografia, v. 14, n. 1, p. 5-18, 2008. 
ROSS, Jurandyr L.S. Análise empírica da fragilidade dos ambientes naturais antropizados. Rev. do Departamento de Geografia, v. 8, p. 63-74, 1994.

RUMBLE, Heather; ANGEOLETTO, Fabio; CONNOP, Stuart et al. Understanding and applying ecological principles in cities. In: LEMES DE OLIVEIRA, Francisco; MELL, Ian (Eds.). Planning Cities with Nature: Theories, Strategies and Methods. Amsterdam: Springer Nature, 2019.

SAATY, Thomas Lorie. A scaling method for priorities in hierarchical structures. Journal of Mathematical Psychology, v. 15, n. 3, p. 234-281, 1977.

SAATY, Thomas Lorie; VARGAS, Luis G. Estimating Technological Coefficients by the Analytic Hierarchy Process. Socio-Economic Planning Sciences, v. 13, n. 6, p. 333-336, 1979.

SAATY, Thomas Lorie. The Analytic Hierarchy Process - What It Is and How It Is Used. Mathematical Modelling, v. 9, n. 3-5, p. 161-176, 1987.

SANTOS, Alexandre R. dos; LOUZADA, Franciane L.R. de Oliveira; EUGENIO, Fernando C. ArcGis 9.3 Total- Aplicações para Dados Espaciais. 2.ed. Alegre: CAUFES, 2010.

SMYTH, Conor. G.; ROYLE, Stephen. A. Urban landslide hazards: incidence and causative factors in Niterói, Rio de Janeiro State, Brazil. Applied Geography, v. 20, n. 2, p. 95-118, 2000.

SPÖRL, Christiane; ROSS, Jurandyr L.S. Análise comparativa da fragilidade ambiental com aplicação de três modelos. GEOUSP - Espaço e Tempo, v. 15, p. 39-49, 2004.

TRICART, Jean. Ecodinâmica. Rio de Janeiro: IBGE, Diretoria Técnica, SUPREN, 1977.

VASILJEVIC,Tamara Z.; SRDJEVIC, Zorica; BAJC `ETIC, Ratko; MILORADOV, Mirjana V. GIS and the analytic hierarchy process for regional landfill site selection in transitional countries: a case study from Serbia. Environ. Manag., v. 49, n. 2, p. 445-58, 2012.

VICENTE, Luís Eduardo; PEREZ FILHO, Archimedes. Abordagem sistêmica e geográfica. Geografia, v. 28, n. 3, p. 323-344, 2003.

WESTEN, Cees van; CASTELLANOS, Enrique; KURIAKOSE, Sekhar L. Spatial data for landslide susceptibility, hazard, and vulnerability assessment: an overview. Engineering Geology, v. 102, n. 3-4, p. 112-131, 2008.

XU, Kai; KONG, Chunfang; LI, Jiangfeng et al. Suitability evaluation of urban construction land based on geo-environmental factors of Hangzhou, China. Computers \& Geosciences, v. 37, n. 8, p. 992-1002, 2011.

ZHANG, Wen; CHEN, Jian-ping; WANG, Qing; AN, Yuke. Susceptibility analysis of large-scale debris flows based on combination weighting and extension methods. Natural Hazards, v. 66, n. 2, p. 1073-1100, 2012.

Data de submissão: 03/ mar./ 2019

Data de aceite: 19/ ago./ 2019 